\title{
Facilitators and barriers for emergency department clinicians using a rapid chest pain assessment protocol: qualitative interview research
}

\author{
Julia Crilly ${ }^{1,2^{*}}$, Jaimi H. Greenslade ${ }^{3,4}$, Sara Berndt ${ }^{4}$, Tracey Hawkins ${ }^{4}$ and Louise Cullen $3,4,5$
}

\begin{abstract}
Background: Guideline-based processes for the assessment of chest pain are lengthy and resource intensive. The IMProved Assessment of Chest Pain Trial (IMPACT) protocol was introduced in one Australian hospital Emergency Department (ED) to more efficiently risk stratify patients. The theoretical domains framework is a useful approach to assist in identifying barriers and facilitators to the implementation of new guidelines in clinical practice. The aim of this study was to understand clinicians' perceptions of facilitators and barriers to the use of the IMPACT protocol.

Methods: Guided by the theoretical domains framework, semi-structured interviews with nine ED clinical staff (medical and nursing) were undertaken in 2016. Content analysis was conducted independently by two researchers to identify those theoretical domains that facilitated or hindered protocol use.

Results: Domains most often reported as fundamental to the use of the IMPACT protocol included 'social/professional role and identity', 'environmental context and resources' and 'social influences'. These factors seemingly influenced professional confidence, with participants noting 'goals' that included standardisation of practice, enhanced patient safety, and reduced need for unnecessary testing. The domain 'environmental context and resources' also contained the most noted barrier - the need to inform new members of staff regarding protocol use. Opportunities to overcome this barrier included modelling of protocol use by staff at all levels and education - both formal and informal.

Conclusions: A range of domains were identified by ED staff as influencing their chest pain management behaviour. Fundamental to its use were champions/leaders that were trusted and accessible, as well as social influences (other staff within ED and other specialty areas) that enabled and supported protocol use. Research investigating the implementation and perceived use of the protocol at other sites, of varied geographical locations, is warranted.
\end{abstract}

Keywords: Emergency department, Qualitative, Chest pain, Acute coronary syndrome, Theoretical domains framework

\section{Contributions to the literature}

- Consistency of practice in managing patients with chest pain in busy emergency departments can be challenging.

- Using the well-recognised theoretical domains framework, facilitators and barriers to the

\footnotetext{
* Correspondence: julia.crilly@health.qld.gov.au

${ }^{1}$ Department of Emergency Medicine, Gold Coast Health, 1 Hospital Blvd, Southport, QLD 4215, Australia

${ }^{2}$ Menzies Health Institute Queensland, Griffith University, Gold Coast 4222, QLD, Australia

Full list of author information is available at the end of the article
}

implementation and use of a new chest pain protocol were identified.

- Fundamental to protocol use were trusted and accessible leaders, as well as social influences internal and external to the emergency department.

\section{Background \\ Acute coronary syndrome (ACS) is the most common acute presentation of coronary heart disease and the lar- gest single cause of death in Australia [1]. Over 1200 pa- tients present to Australian emergency departments (EDs) every day for investigation of ACS ( 6\% of the 7.8}

(c) The Author(s). 2020 Open Access This article is distributed under the terms of the Creative Commons Attribution 4.0 International License (http://creativecommons.org/licenses/by/4.0/), which permits unrestricted use, distribution, and 
million ED presentations per year [2]), yet less than 15\% will ultimately have the diagnosis confirmed [3]. Historically, risk stratification processes for the identification of patients with ACS required physicians to conduct a detailed clinical assessment incorporating historical features, risk factors, electrocardiography (ECG), and serial troponin testing over at least $6-12 \mathrm{~h}$ when using sensitive troponin assays [4-6]. Those with negative results after this initial assessment did not have a diagnosis of acute myocardial infarction but were still at risk for shortand long-term events [7-9]. Therefore, guidelines recommended an objective test in the form of functional or anatomical testing for coronary artery disease [10, 11]. While this approach stratified patients to a near zero short-term risk of ACS, the investigative strategy resulted in a long median length of stay $(27.8 \mathrm{~h}$ per patient) and incurred high financial costs (median of $\$ 2443$ per patient) [3].

ED overcrowding has become a global problem [12] meaning that strategies to improve efficiency within EDs are imperative. There also has been a culture shift towards using evidence-based practice to improve patient outcomes. In the area of chest pain assessment, a number of accelerated strategies have been proposed to reduce the time taken to risk stratify patients [13-15]. One such approach was the IMProved Assessment of Chest pain Trial (IMPACT) strategy, trialled in an Australian ED. [16] IMPACT provided new criteria for the risk stratification and management of patients at low- to intermediate-risk for ACS. No change was made for high-risk patients who were risk stratified and managed according to current standard care. Patients without high-risk features who were 1) under 40 years of age with 2) no renal failure and 3) no diabetes were considered low risk. Such individuals underwent zero and twohour ECG and biomarker testing and were discharged with no further testing if results were normal. Intermediate risk patients were those patients with no high-risk features who were 1) over 40 years of age, 2) under 40 years of age with an estimated glomerular filtration rate (eGFR) $>60 \mathrm{~mL} / \mathrm{min}$, or 3) under 40 years of age with diabetes. Such individuals underwent 0 and $2 \mathrm{~h}$ ECG and biomarker testing followed by inpatient stress testing [16]. Using this protocol, 76\% $(n=1033)$ of patients presenting to the ED with chest pain were classified as low or intermediate risk and could undergo accelerated testing [16]. There were no ACS events within 30 days of presentation in the low-risk group and $14(1.8 \%)$ in the intermediate-risk group. The median hospital length of stay was $5.1 \mathrm{~h}$ and $7.7 \mathrm{~h}$ for the low- and intermediate-risk groups, respectively [16]. When compared against a traditional diagnostic approach [17] of historical controls, for low and intermediate risk patients, hospital length of stay reduced from a median of $24.3 \mathrm{~h}$ prior to implementation of the protocol to $7.2 \mathrm{~h}$ after implementation of the protocol. Furthermore, the expected costs reduced from $\$ 3454$ per patient pre-implementation to $\$ 2225$ postimplementation of the protocol [18]. With the protocol being considered safe, efficient and cost effective, it was implemented as standard care in 2014.

The translation of research into clinical practice can be difficult with evidence showing that it can take around 17 years for innovation to impact patient care [19]. Incorporating protocols into guidelines does not guarantee acceptance; clinicians may not be aware of guidelines, may lack the confidence to act on them, or may not have the knowledge to apply them correctly [20]. Further, findings from tightly controlled clinical trials that only recruit a subset of all patients may not be as successful once implemented within standard care. It may be unwise to invest time and costs to achieve effective translation of a protocol if the benefits seen during the research trial are not as strong when implemented into standard care. Theoretically based frameworks to inform the development, implementation or evaluation of protocols / guidelines and to identify the barriers and enablers to guideline use are therefore helpful when looking to embed research into clinical practice.

The theoretical domains framework has been used to identify barriers and enablers to the implementation of healthcare interventions such as: guidelines for family therapy for families of people with schizophrenia in the community mental health setting [21], guidelines for blood transfusion in the Intensive Care Unit (ICU) setting [22], and safe prescribing of hospital trainee doctors [23]. The use of the theoretical domains framework is relatively new to the ED literature. In the ED setting it has been used for a range of purposes such as to evaluate the use of the Canadian computed tomography $(\mathrm{CT})$ head rule [24], explore factors that influence the use of recommendations for managing mild traumatic brain injury [25], identify barriers and facilitators to the implementation of a screening tool for older people at risk of functional decline and readmission [26], conceptualise and evaluate factors impacting on implementation of a chest pain assessment protocol [27], and guide the development of an intervention to enhance care delivery for people with stroke [28]. The aim of this study was to use the theoretical domains framework to examine clinicians' use of the IMPACT protocol, whether there were any barriers or enablers to protocol use, and whether there are further opportunities to implement IMPACT.

\section{Methods \\ Design}

This qualitative study was guided by a previous retrospective process evaluation undertaken in the ED environment that used the theoretical domains framework [24]. The theoretical domains framework [29] was used 
to underpin our study as it provides a theoretic approach to ensure that a wide range of theoretical explanations for behaviour are considered. Study write up followed the Standards for the Reporting of Qualitative Research (SRQR) guidelines [30].

\section{Participants}

Participants invited include staff (doctors and nurses) employed on a full-time or part-time basis in the Emergency and Trauma Centre (ETC) at the Royal Brisbane and Women's Hospital. All staff were informed about the study via an internal email sent from the ETC medical and nursing directors to staff. Within the email, these directors indicated their support of the project and approval of non-clinical time to participate in an interview. A study information sheet was attached to the email and included contact details of the research team so that staff could advise of their willingness to be interviewed. An interview schedule was arranged by a member of the research team. To enable a range of responses, a personal approach was also used to invite other staff. Participants thus comprised a convenience sample. Participants were recruited until data saturation was reached.

All participants were informed that participation in the study was voluntary and would not impact on their employment at the hospital. Individuals were provided information in verbal and written format, offered opportunity to ask any questions, and provided written consent.

\section{Data collection}

Data were collected via one-on-one, face-to-face, semistructured interviews over a two-week period in 2016. Interviews were conducted by a $\mathrm{PhD}$ prepared researcher with previous experience as an ED nurse (JC) in a private room (to maintain privacy and confidentiality and to avoid interruptions) in the ETC. Each interview was voice recorded and transcribed verbatim by an independent assistant. If required, participants were asked to verify aspects of the interview to enhance clarification and interpretation. Transcribed interviews were de-identified.

Semi-structured interview questions were developed to enable an understanding of behaviour change [29] regarding their assessment of acute coronary syndrome, and in particular the IMPACT protocol. Interview questions were adapted from those used in past research [31] (see Additional file 1). Questions were piloted with one senior doctor and a nurse to assess clarity. Examples of questions included: What is your understanding of the recommendations regarding accelerated chest pain assessment? Where and how did you learn about the pathway? To what extent do you think the chest pain pathway is being implemented? Can you give me a recent example of it happening? What problems have you encountered? What would happen if you didn't use the pathway? Would you say the benefits outweigh the costs? Do you think that this pathway could be implemented in other hospitals?

\section{Rigor}

Rigor was maintained through the use of recommended strategies [32-34]. An external interviewer (not employed at the hospital) performed the interviews to minimise the risk of bias and threat of potential interviewee - interviewer clinical professional relationship concerns. To enhance credibility, different multi-disciplinary perspectives were purposively sought and participant quotes from various sources are presented. Other researchers were involved with the analysis to reflect dependability. Participant characteristics and contextual data are reported so that transferability can be considered by readers.

\section{Data analysis}

Interview data were analysed using the theoretical domains framework [29]. Within this framework, there are 14 domains that explain behaviour change. These include 1) knowledge; 2) skills; 3) social/professional role and identity; 4) beliefs about capabilities; 5) optimism; 6) beliefs about consequences; 7) reinforcement; 8) intentions; 9) goals; 10) memory, attention and decision processes; 11) environmental context and resources; 12) social influences; 13) emotion; and 14) behavioural regulation. The interview questions aimed to identify information relevant to these domains. Content analysis was conducted independently by two researchers (SB and JC) to identify theoretical domains and constructs as well as to identify which domains were barriers and or enablers to change. It also involved identifying patterns across data sets (e.g. frequency of noted constructs within each domain in each and all interviews). The domains and constructs coded by each researcher were compared and discussed with consensus reached using a third researcher (JG) where required. Thematic analysis was performed in six phases including familiarization with data, generating initial codes, searching for themes among codes, reviewing themes, defining and naming themes, and producing the final report [35].

\section{Results}

A total of nine participants were interviewed. These participants represented both medical $(n=4)$ and nursing $(n=5)$ staff working at the ETC where the protocol was implemented. Three participants were male and the average age of participants was 40 years (SD: 10.3). The average years of experience in their profession was 17 (SD: 9.2), with 12.6 years (SD: 6.6) working in the ED. 
Interviews lasted on average $32 \mathrm{~min}$ (range: 22 to 44 $\min )$.

Of the 14 domains, 8 were identified as relevant to the context of chest pain assessment and management and the use of the IMPACT protocol (see Table 1); 5 domains clearly reflected enablers to protocol use. There was overlap in three domains (memory, attention and decision and processes; skills; and environmental context and resources) where both barriers and enablers were evident. The key themes underpinning these domains, along with examples of quotes are presented in Table 1.

\section{Enablers to protocol use}

Domains that reflected enabling facets of the implementation of the IMPACT protocol included i) knowledge, ii) social professional role and identity, iii) beliefs about capabilities, iv) goals, and v) social influences.

\section{Knowledge}

All participants were aware of the IMPACT protocol and used it daily when working clinically. Participants were aware of the branches within the pathway (i.e. high risk, moderate risk, low risk), and most knew the criteria for each. Aspects noted to underpin protocol use included: education provided regarding the protocol; continued and visible access to the protocol (enlarged, easy to follow, colour print-out located in areas where a patient likely to require protocol use are located); and that it was driven by a respected and trusted leader within the field located in their department.

\section{Social professional role and identity}

Despite the variation in interview participants (nurses and doctors, junior and senior staff), all noted that they had a role to play regarding IMPACT - be it assessment, management or referral. Participants were quite clear in terms of their professional boundaries but noted that IMPACT fostered a sense of teamwork and cooperation. The reduced variation in practice that IMPACT offered was welcomed by staff in the ED and the protocol provided professional confidence that assisted with decision-making and collaboration with inpatient specialists. One of the key facilitators of the protocol was that a trusted professional colleague led it and this increased their motivation to use the protocol.

\section{Beliefs about capabilities}

Participants reported that the protocol was easy to use and empowered them to make decisions. They felt encouraged to initiate the pathway if they felt that the patient was suitable. The IMPACT protocol provided some practitioners with a sense of confidence in managing patients with chest pain. However, one respondent reported that they did not have the confidence to use it except within the context of the treating team. One also noted that relying on a protocol might result in less use of clinical judgment and higher risk of missing a diagnosis.

\section{Goals}

Goals of the IMPACT protocol implementation were noted by participants to include: standardisation of evidence-based practice; improved patient flow, reduced cost and reduced length of stay; enhanced patient outcomes; and the reduced need for unnecessary testing.

\section{Social influences}

The use of IMPACT was normative, with respondents reporting that everyone uses it. Group conformity and social pressure were noted factors to enhance protocol use. Intergroup support from inpatient teams was also highlighted as a facilitator to the protocol. The standardisation of practice that the protocol provided also helped with inter-professional communication.

\section{Cross over}

Three domains contained both barriers and facilitators of protocol use. These included memory, attention and decision and processes; skills; and environmental context and resources.

\section{Memory, attention and decision processes}

There was a strong sense of knowledge of the IMPACT protocol and most participants generally knew the criteria. However, participants reported that they could not always remember the guideline content. They noted that posters placed throughout the department and access to the guideline on the ED electronic repository assisted them when needing to clarify or recall criteria to inform their decision-making. They also welcomed the opportunity for standardisation of practice that assisted decision-making in an area that was previously unclear.

\section{Skills}

Respondents noted that it required specific skills to identify which patients are eligible to be placed on the pathway. This was a barrier for less experienced clinicians who may have difficulty identifying appropriate patients for inclusion. De-skilling was also identified as a concern as the use of a pathway reduced the requirement for clinical decision-making. Skill building through positive interpersonal encounters was identified as a positive aspect of the pathway.

\section{Environmental context and resources}

This domain contained the most noted barrier to protocol use, that is, the need to inform new members of staff. However, there were also facilitators identified to 


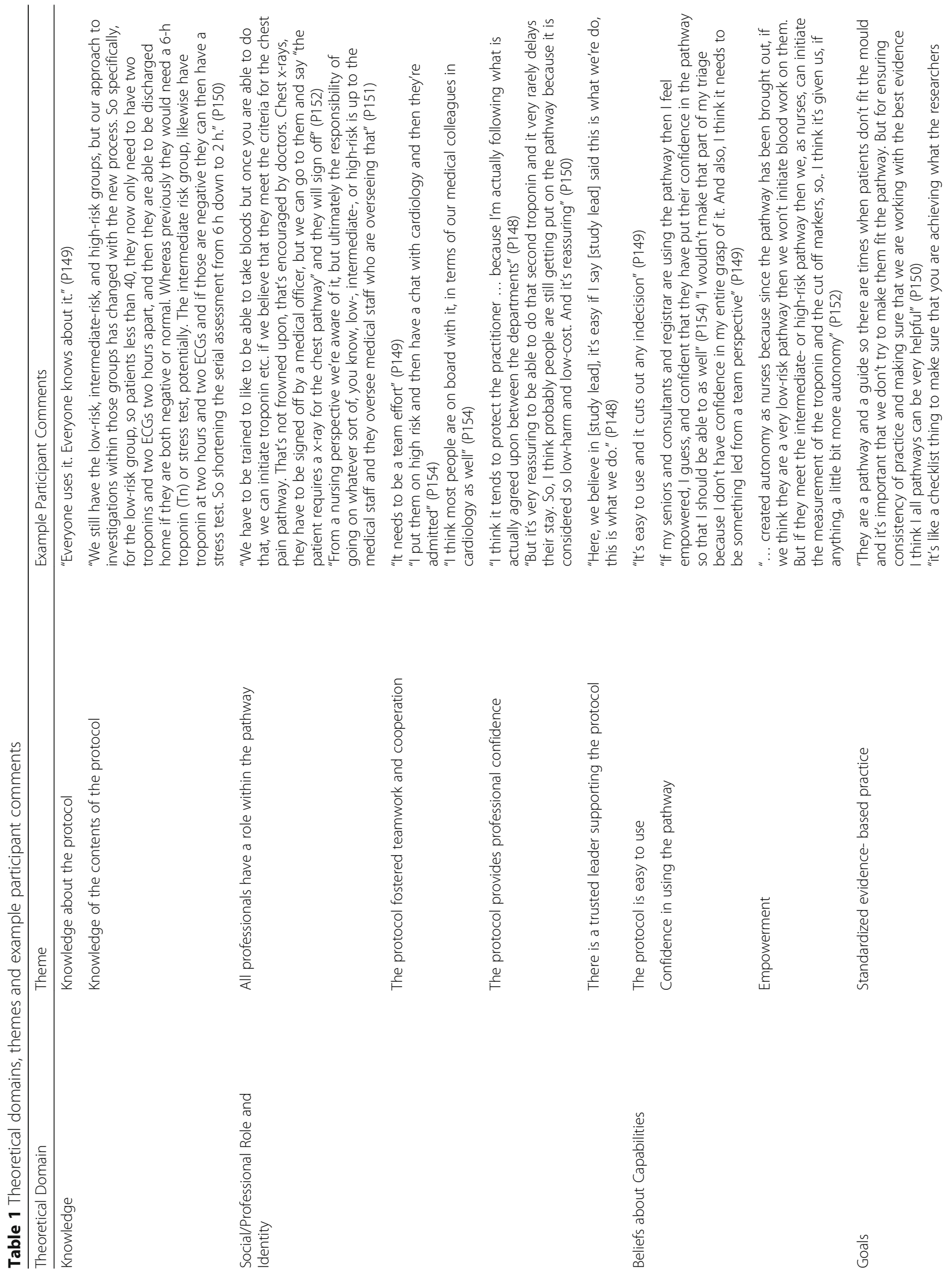




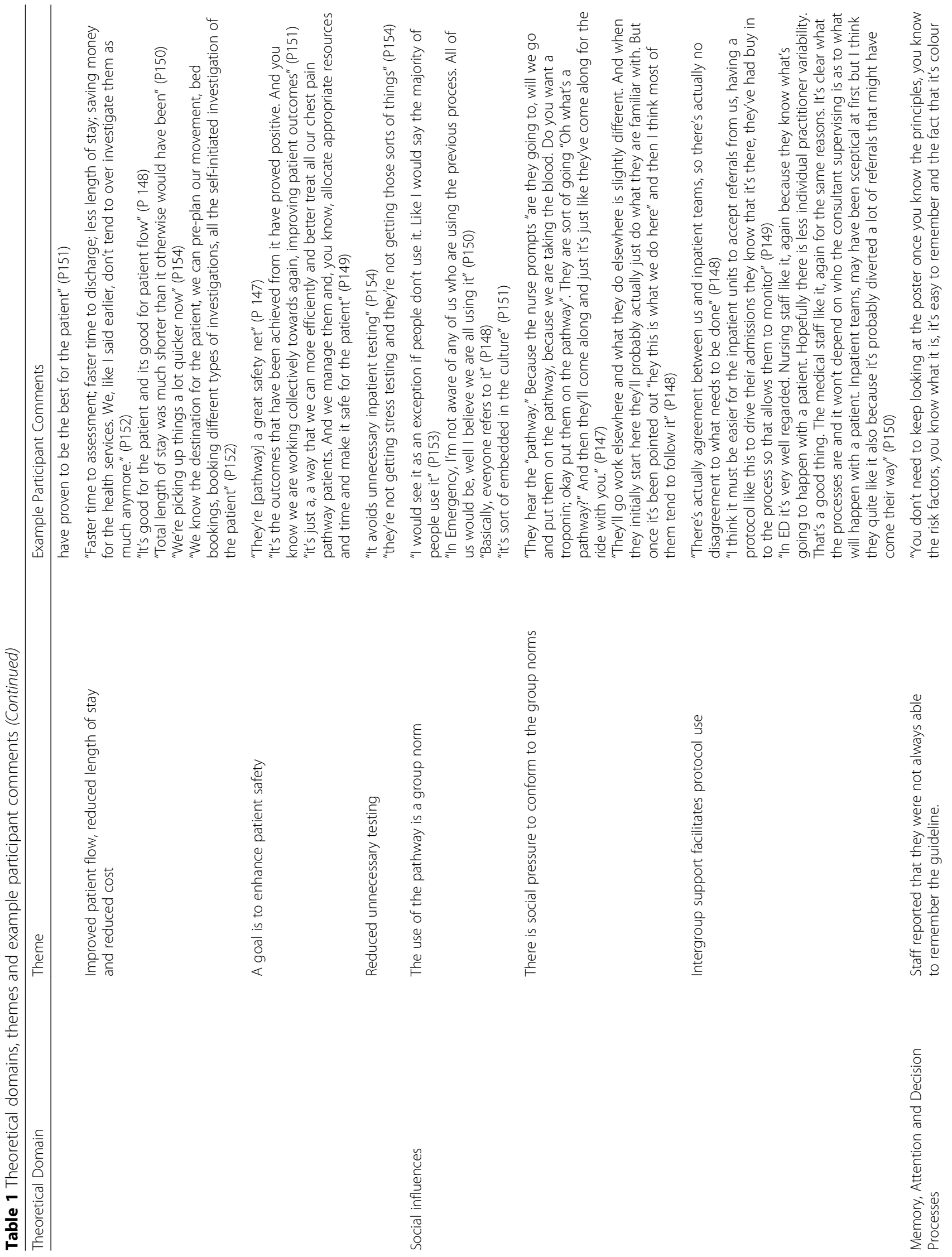




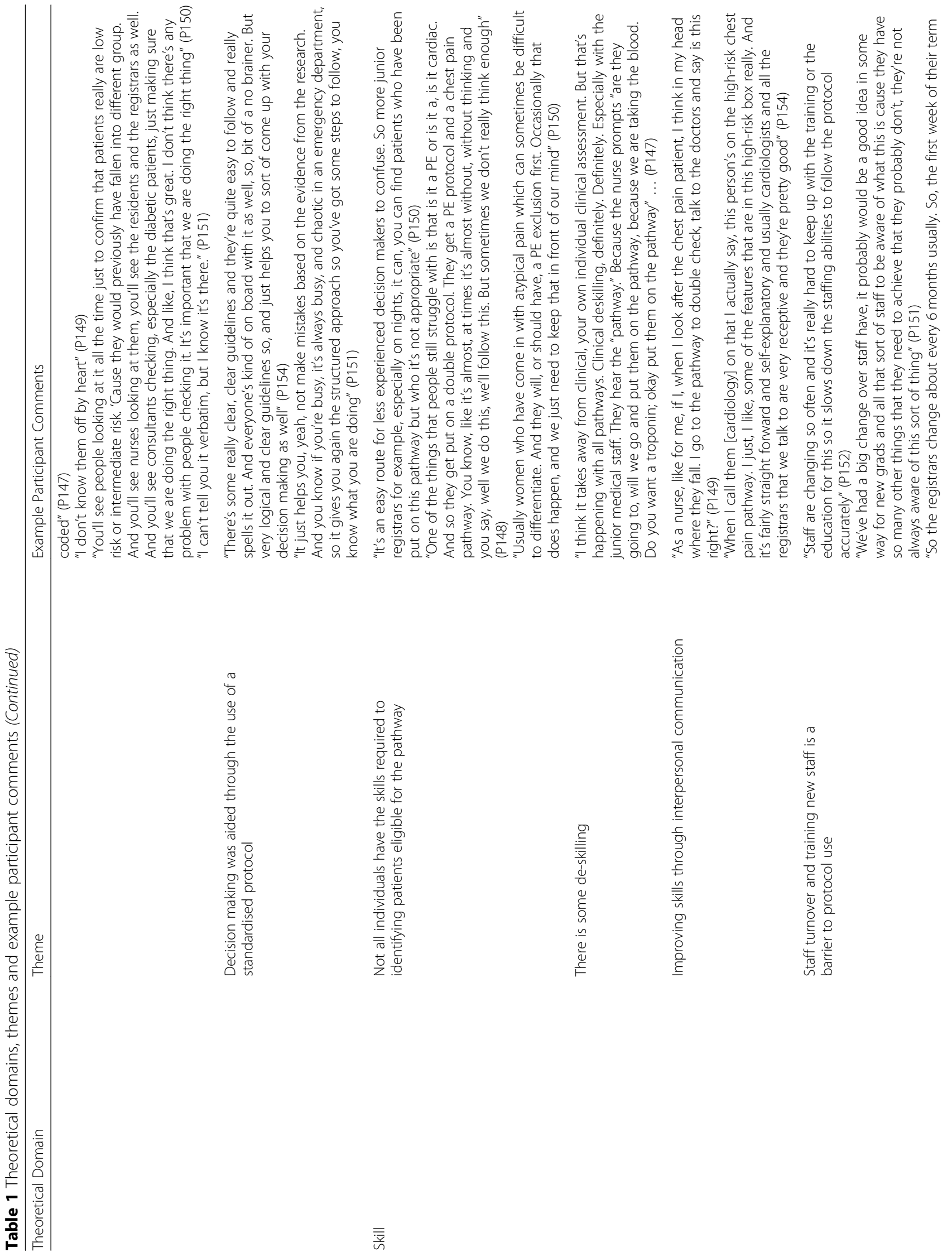


Chilly et al. BMC Health Services Research

(2020) 20:74

Page 8 of 11

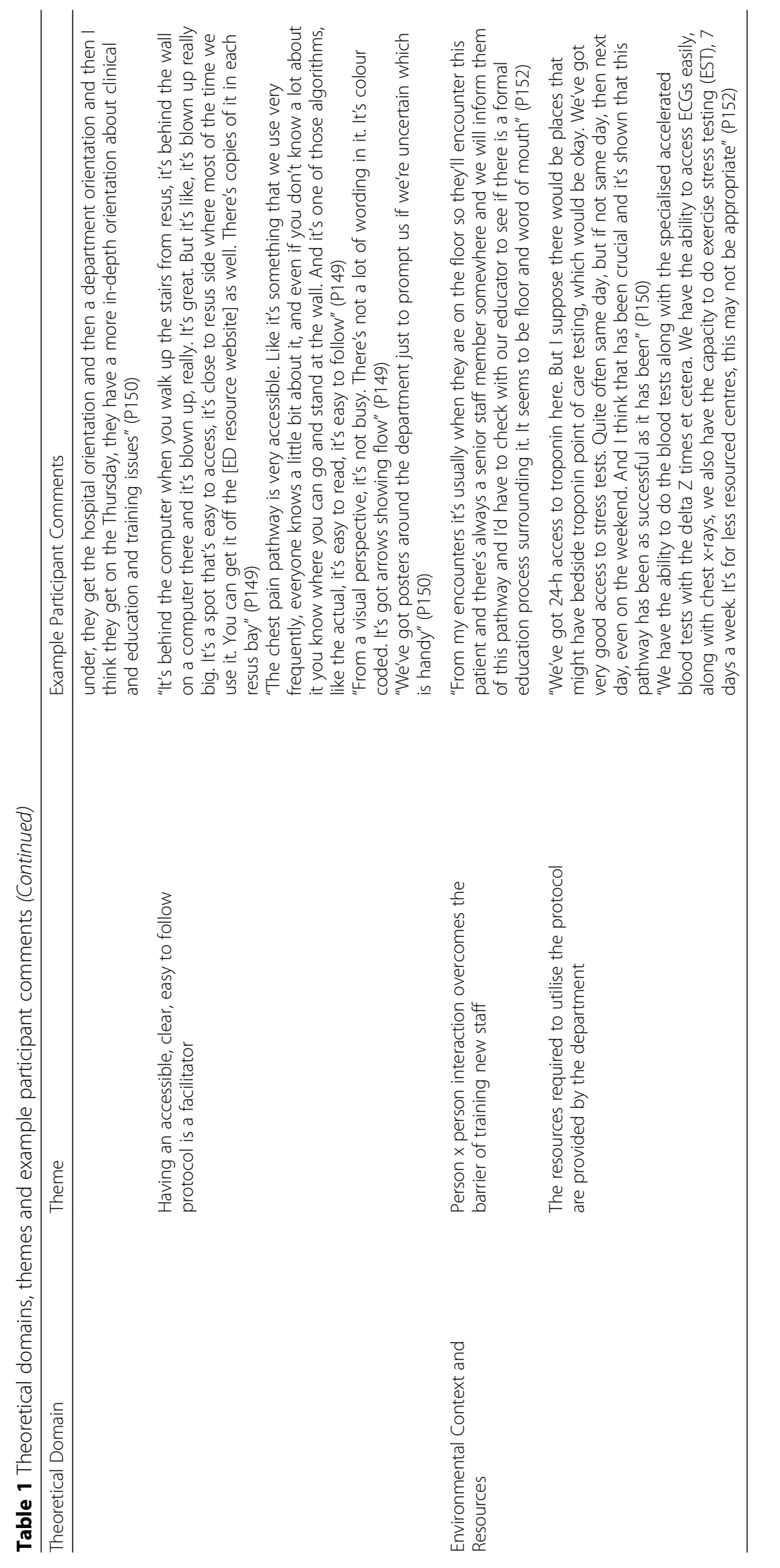


overcome this barrier. These facilitators included the accessibility to a clear, easy to follow protocol that was supported by the organisation. The person-person interaction involved modelling of protocol use by staff at all levels and education - both formal and informal. Another facilitator identified by participants was that resources needed to follow the protocol were readily available within the ED.

\section{Discussion}

The assessment of chest pain comprised considerable research focus, with a number of accelerated pathways having been developed $[13,14,16]$. However, few pathways have been implemented as standard care. The IMPACT pathway has been implemented following positive patient and service outcomes in terms of safety and efficacy [16]. The current study highlights facilitators and barriers to the implementation of this protocol.

This study supports previous ED research [24, 25, 27, 28] in finding that the theoretical domains framework provides a useful approach to retrospectively identify barriers and enablers to protocol use in the ED. It also supports the considerable literature utilising this framework to explain behaviour change across a variety of interventions (e.g. back pain management, blood transfusion practices, prescribing errors, family intervention for people with schizophrenia), population groups (e.g. doctors - General Practitioners, ICU physicians, trainee doctors, mental health team members - social workers, nurses, team managers, psychologists, psychiatrists), and settings (ranging from primary care, hospital setting, ICU, community and mental health) [21-23, 36].

Domains that reflected enabling facets of the implementation of the IMPACT protocol included knowledge, social professional role and identity, beliefs about capabilities, goals, and social influences. Staff reported that they were knowledgeable in the pathway, that they were confident in implementing the protocol, that it strengthened relationships within the department and across departments, and that its use had become normative within the department. These domains have been noted in other research regarding protocol use in the ED. Knowledge and social/professional role and identity have been recognized as key to the successful implementation of a previous chest pain pathway [27] and being confident in applying a clinical decision rule and social influences have been identified as facilitators to using a CT rule [24]. However, Curran et al. [24], noted that while knowledge about the CT rule was high, this was not a key driver to implementation, with various contextual factors outweighing knowledge.

Three domains incorporated both facilitators and barriers in the current study. Cross over identified within a domain is not uncommon. Curran et al. [24], reported that beliefs about the consequences of the Canadian CT head rule were both facilitators (supports decision making and reduces radiation exposure) and barriers (hinders patient flow in the department). Similarly, Craig et al. [28], conducted a review of interventions to manage acute stroke in the ED and identified multiple studies where the environment, context and resources domain and skills domains incorporated both facilitators and barriers. In our study, with regard to memory, being able to remember and act on a new pathway was identified as a barrier. Resources were also identified as a concern; with staff feeling they did not have the resources to train new staff to implement the pathway. These domains (as barriers) have previously been identified in the ED setting [24]. However, it was noted in the current study that the provision of visible and clear information for staff on the protocol were facilitators that alleviated these barriers. Previous research using the theoretical domains framework has noted a number of additional barriers to implementing new pathways or guidelines in the ED that were not identified in the current research. For example, beliefs about consequences, in particular, beliefs about increased time requirements on an already heavy workload, have been identified as barriers [24, 26]. Lack of skills or confidence around implementing new protocols has also been identified as a concern [24, 25]. These barriers may not have emerged in the present study as the IMPACT pathway is a simple accelerated protocol that saves time within the ED. Staff had also undergone extensive training in the pathway from the clinical lead and from research nurses who were involved in trialling the protocol.

Implementation depends on clinicians and managers changing a variety of behaviours [21]. If interventions are to be successful, they need to be grounded in an understanding as to why health professionals do or do not change their behaviour [21]. Historically, studies using the theoretical domains framework tend to focus (understandably) on the barriers, rather than the enablers to practice change. In this study, enabling factors underpinning why health care professionals changed their behaviour included: having knowledge of the protocol, being part of a team that embraced the process, knowing and trusting the change leader, having an awareness that the protocol implemented was evidence based and the ultimate belief that it was what was best for the patient, the ED, and the health system. These are factors for consideration if implementing the IMPACT or other protocols elsewhere.

\section{Limitations}

Limitations to this study include the small sample size, however data saturation was reached, and the sample reflected a depth of clinician types (doctors and nurses) 
and experience (junior and senior). This study was undertaken at one site. Whilst findings may not be generalizable to other EDs where different processes are used for chest pain management, they may be helpful for EDs that intend to implement the IMPACT protocol. Finally, the theoretical domains framework is typically used prior to implementing an intervention designed to improve practice. We used the theoretical domains framework following the implementation of a protocol designed to standardise practice. However, using the protocol for this purpose was useful in identifying where there is further opportunity for improvement, and identifying which domains facilitated implementation and protocol use.

\section{Conclusions}

Findings from this study indicate that staff were knowledgeable about the IMPACT protocol and used it frequently. Whilst staff may not have an in-depth knowledge of requirements of the protocol, the ready access to a variety of resources and education enabled its use. Although there was uncertainty regarding the costbenefits, there was agreement that the standardisation in practice the IMPACT protocol offered was of benefit to the patient, the practitioner and the health service. Imperative to the development and implementation of the protocol was the driver (an experienced staff specialist with an academic background in chest pain) who was seen as a leader, had rapport, and trust of staff at all levels within the ED. Engagement from leaders from other in-patient areas (e.g. cardiology, medicine) was seen as imperative to protocol establishment and subsequent use. Findings from this study can be used to support the implementation of the protocol at other sites as well as further refine and improve the way that the IMPACT protocol is translated into clinical care in the future.

\section{Supplementary information}

Supplementary information accompanies this paper at https://doi.org/10. 1186/s12913-020-4923-2

Additional file 1. List of questions used to guide interviews

\section{Abbreviations}

ACS: Acute coronary syndrome; ECG: Electrocardiogram; ED: Emergency Department; eGFR: estimated glomerular filtration rate; ETC: Emergency and Trauma Centre; IMPACT: Improved Assessment of Chest Pain Trial

\section{Acknowledgements}

We wish to thank staff who agreed to participate in the interviews for this study.

\section{Authors' contributions}

All authors meet the criteria for authorship. JC, JG, and LC conceived and designed the study. JC acquired the data and JC, SB, and JG analysed the data. TH and SB assisted with study design and interpretation of the data. JG,
TH, and LC drafted the work and all authors revised the manuscript for important intellectual content. All authors have read and approved the final manuscript.

\section{Funding}

The study was funded by a research grant from the Emergency Medicine Foundation (Grant \# EMSS-221R24-2015). The funder had no role in the design, collection, analysis, and interpretation of data; in the writing of the manuscript; nor in the decision to submit this manuscript for publication.

Availability of data and materials

The dataset is not publicly available due to confidentiality policies.

Ethics approval and consent to participate

The study protocol was approved by the Royal Brisbane and Women's Hospital Human Research and Ethics Committee and complied with the Declaration of Helsinki. All participants were informed that participation in the study was voluntary and would not impact on their employment at the hospital. Individuals were provided information in verbal and written format, offered opportunity to ask any questions, and provided written informed consent to participate.

\section{Consent for publication}

As part of the consent process, participants were advised that any data provided in the interview would be used to inform a peer-review manuscript

\section{Competing interests}

LC has received research grants from Beckman's and Abbot paid to their institution. All other authors declare no competing interests.

\section{Author details}

'Department of Emergency Medicine, Gold Coast Health, 1 Hospital Blvd, Southport, QLD 4215, Australia. ${ }^{2}$ Menzies Health Institute Queensland, Griffith University, Gold Coast 4222, QLD, Australia. ${ }^{3}$ Institute of Health and Biomedical Innovation and School of Public Health and Social Work, Faculty of Health, Queensland University of Technology, 60 Musk Avenue, Kelvin Grove, QLD 4059, Australia. ${ }^{4}$ Emergency and Trauma Centre, Royal Brisbane and Women's Hospital, Butterfield Street, Herston, QLD 4029, Australia. ${ }^{5}$ School of Medicine, Faculty of Health and Behavioural Sciences, The University of Queensland, 288 Herston Road, Herston, QLD 4006, Australia.

Received: 29 July 2019 Accepted: 21 January 2020

Published online: 31 January 2020

References

1. Australian Institute of Health and Welfare. Australia's Health 2016. In: Australia's Health Series no 15. Cat no. AUS 199. Canberra: AlHW; 2016.

2. Codde J, Bowen S, Lloyd E. Analysis of demand and utilisation of metropolitan emergency departments in Western Australia. Perth: Department of Health; 2006.

3. Cullen L, Greenslade JH, Merollini K, Graves N, Hammett CJ, Hawkins T, et al. Cost and outcomes of assessing patients with chest pain in an Australian emergency department. Med J Aust. 2015;202:427-32.

4. Anderson JL, Adams CD, Antman EM, Bridges CR, Califf RM, Casey DE Jr, et al. ACC/AHA 2007 guidelines for the management of patients with unstable angina/non-ST-elevation myocardial infarction: a report of the American College of Cardiology/American Heart Association task force on practice guidelines. J Am Coll Cardiol. 2007;50(7):e1-e157.

5. Thygesen K, Alpert J, White H. Universal definition of myocardial infarction. J Am Coll Cardiol. 2007;50(22):2173-95.

6. Rapezzi C, Biagini E, Branzi A. Guidelines for the diagnosis and treatment of non-ST-segment elevation acute coronary syndromes: the task force for the diagnosis and treatment of non-ST-segment elevation acute coronary syndromes of the European Society of Cardiology. Eur Heart J. 2008:29(2):277-8.

7. Manini AF, McAfee AT, Noble VE, Bohan JS. Prognostic value of the duke treadmill score for emergency department patients with chest pain. J Emerg Med. 2010;39:135-43. 
8. Jeetley P, Burden L, Senior R. Stress echocardiography is superior to exercise ECG in the risk stratification of patients presenting with acute chest pain with negative troponin. Eur J Echocardiogr. 2006;7:155-64.

9. Lindahl $B$, Venge $P$, James $S$. The new high-sensitivity cardiac troponin $T$ assay improves risk assessment in acute coronary syndromes. Am Heart J. 2010;160(2):224-9.

10. Amsterdam EA, Kirk JD, Bluemke DA, Diercks D, Farkouh ME, Garvey JL, et al. Testing of low-risk patients presenting to the emergency department with chest pain: a scientific statement from the American Heart Association. Circulation. 2010;122(17):1756-76.

11. Chew DP, Scott IA, Cullen L, French JK, Briffa TG, Tideman PA, et al. National Heart Foundation of Australia \& Cardiac Society of Australia and new Zealand: Australian clinical guidelines for the management of acute coronary syndromes 2016. Heart Lung Circ. 2016;25(9):895-951.

12. Yarmonammadian M, Rezaei F, Haghshenas A, Tavakoli N. Overcrowding in emergency departments: a review of strategies to decrease future challenges. J Res Med Sci. 2017;22:23.

13. Than M, Cullen L, Aldous S, Parsonage WA, Reid CM, Greenslade J, et al. 2hour accelerated diagnostic protocol to assess patients with chest pain symptoms using contemporary troponins as the only biomarker: the ADAPT trial. J Am Coll Cardiol. 2012;59(23):2091-8.

14. Backus BE, Six AJ, Kelder JC, Mast TP, van den Akker F, Mast EG, et al. Chest pain in the emergency room: a multicenter validation of the HEART score. Crit Pathw Cardiol. 2010;9(3):164-9.

15. Reichlin T, Twerenbold R, Wildi K, Rubini Gimenez M, Bergsma N, Haaf P et al. Prospective validation of a 1-hour algorithm to rule-out and rule-in acute myocardial infarction using a high-sensitivity cardiac troponin T assay. CMAJ. 2015;187(8):E243-52

16. Cullen L, Greenslade J, Hawkins T, Hammett C, O'Kane S, Ryan K, et al. IMProved assessment of chest pain trial (IMPACT): an intervention study of a new accelerated protocol for patients with possible acute coronary syndrome. Med J Aust. 2017:207:195-200.

17. Chew DP, Aroney CN, Aylward PE, Kelly AM, White HD, Tideman PA, et al. 2011 addendum to the National Heart Foundation of Australia/Cardiac Society of Australia and new Zealand guidelines for the management of acute coronary syndromes (ACS) 2006. Heart Lung Circ. 2011;20(8):487-502.

18. Cheng Q, Greenslade JH, Parsonage WA, Brarnett AG, Merollini K, Graves $\mathrm{N}$, et al. Change to costs and lengths of stay in the emergency department and the Brisbane protocol: an observational study. BMJ Open. 2016;6:e009746.

19. Morris ZS, Wooding S, Grant J. The answer is 17 years, what is the question: understanding time lags in translational research. J R Soc Med. 2011;104:510-20.

20. Kalassian KG, Demsizov T, Angus DC. Translating research evidence into clinical practice: new challenges for critical care. Crit Care. 2002;6:11-4

21. Miche S, Pilling S, Garety P, Whitty P, Eccles MP, Johnston M, et al. Difficulties implementing a mental health guideline: an exploratory investigation using psychological theory. Implement Sci. 2007;2:8.

22. Islam R, Tinmouth AT, Francis JJ, Brehaut JC, Born J, Stockton C, et al. A cross-country comparison of intensive care physicians' beliefs about their transfusion behaviour: a qualitative study using the theoretical domains framework. Implement Sci. 2012;21(7):93.

23. Duncan EM, Francis JJ, Johnston M, Davey P, Maxwell S, McKay GA, et al. Learning curves, taking instructions, and patient safety: using a theoretical domains framework in an interview study to investigate prescribing errors among trainee doctors. Implement Sci. 2012;7:86.

24. Curran JA, Brehaut J, Patey AM, Osmond M, Stiell I, Grimshaw JM. Understanding the Canadian adult CT head rule trial: use of the theoretica domains framework for process evaluation. Implement Sci. 2013;8:25.

25. Tavender EJ, Bosch M, Gruen RL, Green SE, Michie S, Brennan SE, et al. Developing a targeted, theory-informed implementation intervention using two theoretical frameworks to address health professional and organisational factors: a case study to improve management of mild traumatic brain injury in the emergency department. Implement Sci. 2015;10:74.

26. Kirk JW, Sivertsen DM, Petersen J, Nilsen P, Petersen HV. Barriers and facilitators for implementing a new screening tool in an emergency department: a qualitative study applying the theoretical domains framework. J Clin Nurs. 2016;25:2786-97.

27. Skoien W, Page K, Parsonage W, Ashover S, Milburn T, Cullen L. Use of the theoretical domains framework to evaluate factors driving successful implementation of the Accelerated Chest pain Risk Evaluation (ACRE) project. Implement Sci. 2016;11:136.

28. Craig LE, Mclnnes E, Taylor N, Grimley R, Cadilhac DA, Considine J, et al. Identifying the barriers and enablers for a triage, treatment, and transfer clinical intervention to manage acute stroke patients in the emergency depatment: a systematic review using the theoretical domains framework (TDF). Implement Sci. 2016;11:157.

29. Michie S, Johnston M, Abraham C, Lawton R. Making psychological theory useful for implementing evidence based practice: a consensus approach. Qual Saf Health Care. 2005;14:26-33.

30. O'Brien BC, Harris IB, Beckman TJ, Reed DA, Cook DA. Standards for reporting qualitative research: a synthesis of recommendations. Acad Med. 2014:89:1245-51.

31. Michie S, Berentson-Shaw J, Pilling S, Feder GS, Dieppe P, Raine R, et al. Turning evidence into recommendations: protocol of a study guideline development groups. Implement Sci. 2007;2:29.

32. Graneheim UH, Lundman B. Qualitative content analysis in nursing research: concepts, procedures and measures to achieve trustworthiness. Nurse Educ Today. 2004;24(2):105-12.

33. Noble $\mathrm{H}$, Smith J. Issues of validity and reliability in qualitative research. Evid Based Nurs. 2015;18(2):34-5.

34. Krefting L. Rigor in qualitative research: the assessment of trustworthiness. Am J Occup Ther. 1991;45(3):214-22.

35. Braun V, Clark V. Using thematic analysis in psychology. Qual Res Psychol. 2006;3:77-101.

36. French SD, Green SE, O'Connor DA, McKenzie JE, Francis JJ, Michie S, et al. Developing theory-informed behaviour change interventions to implement evidence into practice: a systematic approach using the theoretical domains framework. Implement Sci. 2012;7:38

\section{Publisher's Note}

Springer Nature remains neutral with regard to jurisdictional claims in published maps and institutional affiliations.
Ready to submit your research? Choose BMC and benefit from:

- fast, convenient online submission

- thorough peer review by experienced researchers in your field

- rapid publication on acceptance

- support for research data, including large and complex data types

- gold Open Access which fosters wider collaboration and increased citations

- maximum visibility for your research: over $100 \mathrm{M}$ website views per year

At $\mathrm{BMC}$, research is always in progress.

Learn more biomedcentral.com/submissions 